\title{
Point: How Quality Reporting Made Me a Better Doctor
}

\author{
David R. Scrase, MD \\ Internal Medicine and Geriatrics, The University of New Mexico Medical School, Albuquerque, New Mexico \\ Ann Fam Med 2017;15:204-206. https://doi.org/10.1370/afm.2088.
}

I have spent most of my medical career working with health care teams to improve patient outcomes, in hospitals, outpatient clinics, an insurance company network, health system, skilled nursing facility, and in home visits. It is my contention that quality reporting certainly can lead to better outcomes for patients, but it does not always accomplish that goal. How can such reporting improve outcomes, and why doesn't it always work?

As Medicare and other payers move to pay practitioners based on "quality scores" and "quality outcomes," understanding how to make quality reporting more effective ought to be a critical priority for health care practitioners and health systems. The fact that we are increasingly being paid according to these systems, but are still debating their effectiveness, is a call to action..$^{1,2}$

Figure 1 outlines a model that I have used over the past 30 years to improve quality of patient care. Let us walk through the model step by step.

\section{STEP 1. AGREE ON THE STANDARD OF CARE}

The first step is to assemble a group of physicians to clearly agree on the current standard of care. How often should a mammogram be obtained, and on whom? What level of $\mathrm{A}_{1 \mathrm{c}}$ represents "good control?" What is the age range within which an individual should receive screening for colon cancer? There are divergent guidelines available for each of these questions, therefore physicians being measured must have input into what, and how, we will measure "good performance." Most primary care groups will now agree

Conflicts of interest: author reports none.

\section{CORRESPONDING AUTHOR}

David R. Scrase, MD

Internal Medicine and Geriatrics

The University of New Mexico Medical School

Albuquerque, New Mexico

DScrase@salud.unm.edu that the US Preventive Services Task Force criteria are at least a good place to start, but the importance of the face-to-face conversation cannot be underestimated. Finding quality measures that can be assembled in an electronic fashion using reliable methods, without the need for manual chart review, is the most important first step.

\section{STEP 2: COLLECT AND PROVIDE INITIAL REPORTING OF THE DATA}

This is a very challenging step. In the world of electronic medical records, the quality measure and its definition may or may not be already configured properly to match the criteria agreed upon by practitioners in Step 1 . This process is easier within a single organization, with an exponential increase in complexity when data are drawn from more than one system. When the HEDIS quality measure set was developed, medicine experienced a major leap forward in measurement definition, with a corresponding complexity of programming and data analysis required to extract results appropriately. The complexity of a simple measure can be overwhelming.

\section{STEP 3: ARGUE ABOUT THE DATA}

(This is my favorite part.) Over the past 30 years, I have discovered dozens of unique barriers inherent in reporting a given measure correctly. For example, there may be issues in the accurate reporting of the number of patients eligible for a pneumococcal-23 vaccine, the number of patients receiving the immunization (what if someone gets 2?), and even errors in dividing the former by the latter on an individual physician basis. Further, this is where the input of practitioners receiving the reports becomes most helpful. "I've never even heard of that patient," can be a legitimate argument in some circumstances. On the other hand, if the primary care physician has received a capitation payment for a 70 year-old patient over the past 5 years, and the 
patient has no contraindication, but has never received the vaccine, then the subsequent discussion may explore the area of population management. I believe that when we start arguing about the data, we are halfway there. There simply is no route that can take us from "no data" to "good data" without passing through "bad data." There just isn't. Instead of just rejecting the "bad data," those of us being measured must help those who are doing the measuring become more accurate. They cannot do it without us.

\section{STEP 4: IMPROVE THE DATA}

This is a critical step. Every error in the data must be seen as a gift to improving the reporting process. I could fill a page with all of the errors that I have seen through the years. My favorite comes from the time I was a Chief Medical Officer for a New Mexico health plan, and found that our system contained 51 different spellings for Ophthalmology. Worse, I received strident arguments from my provider services department regarding $m y$ preferred spelling, which was, as it turned out, the only one in the dictionary. Erroneous patient names, birthdates, provider names, lab data values, or any other error can invalidate almost any measure's accuracy. Every single error must be repaired! At our health plan, we introduced a drop down menu that provided only one spelling for Ophthalmology. That fix was easy, but others may be more difficult. We may want to include people with asthma, COPD, or diabetes and those who have had a splenectomy in the group of people under 65 who are eligible to be included in the denominator of the pneumococcal-23 vaccine measure.

\section{Figure 1. Model to improve quality of patient care.}

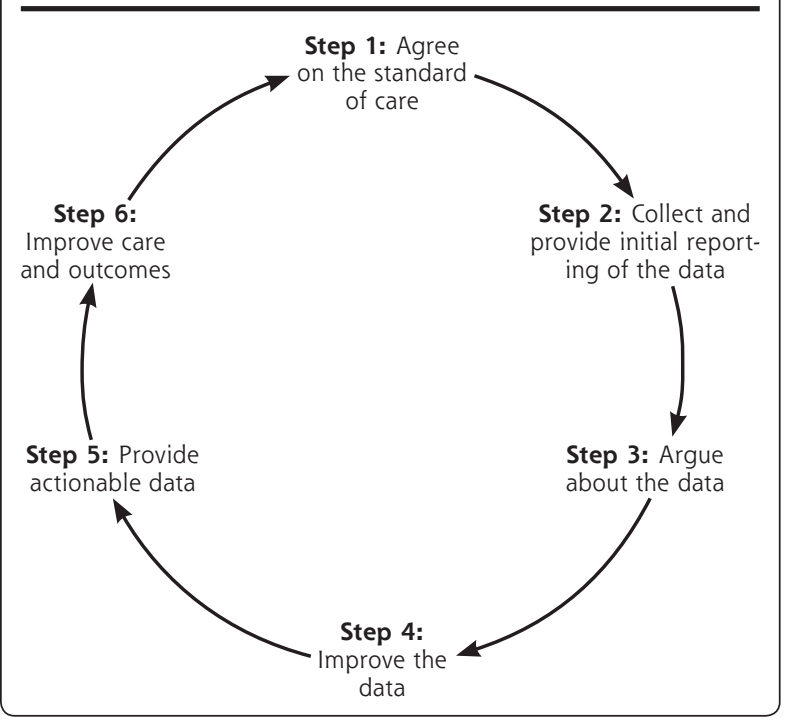

Can we rely on the accuracy of those ICD-10 codes in the EMR or on the claim, or both, or neither?

When I hear that quality reporting "doesn't work" to improve patient outcomes because the data are unreliable, I still hope that we are taking what we learn from the errors and revising our algorithms to continuously improve such reporting. While 100\% accuracy may not be achievable, I can say with some confidence that there is a difference in the effectiveness of practice between 2 physicians with mammography rates of $21 \%$ and $88 \%$. Most data errors are systematic and tend to affect all physicians equally.

\section{STEP 5: PROVIDE ACTIONABLE DATA}

This is the most commonly omitted step in the process, and the single most important reason that quality reporting has not yet won the full respect of physicians. If I have 1,000 patients that are eligible for pneumococcal-23 vaccine (I am a geriatrician after all), and am told that my vaccination rate is $50 \%$, or $90 \%$, I find that data relatively useless. What I and every other practitioner need is a list of those patients who are believed to bave not received the targeted intervention, and a commitment from those producing the reports to update their data when we find exceptions.

\section{STEP 6: IMPROVE CARE AND OUTCOMES}

Even the most ardent detractors of quality metrics would likely admit that a comprehensive list of 100 patients needing a preventive or disease treating intervention that is 90 percent accurate could help improve their patient care. In medical groups, or States, or national health care systems that have made the most progress using such data to improve patient care, the physician or other PCP rarely is involved in the basic process of going through the lists, contacting the patients, and ensuring that they come in for the recommended testing or treatment. Trained care managers or case managers are often doing this work in a highly effective fashion. One of the core tenets of the PatientCentered Medical Home is the improvement in patient outcomes with data to guide and manage prevention and health care interventions at the population level.

It is my thesis that only by using the 6 steps described above can quality reporting lead to better patient outcomes. New Mexico saw the provision of actionable data to physician offices improve overall mammography and immunization rates in our patient population within a few years. There are few well-designed studies demonstrating the presence or absence of patient care benefits from quality reporting. I am proud that Medicare, our nation's largest payer, 
has taken the lead in focusing on patient care outcomes and attaching financial incentives to those providers, hospitals, and nursing homes achieving good results, or avoiding certain poor results or complications.

The fact that there remain so many points and counterpoints regarding quality reporting, ${ }^{3}$ and that such reporting is already in use for determining physician and other practitioner payments should, I believe, compel us all to do our part to improve these systems, so that we all find ourselves happily on the "point" side of the argument in the not-too-distant future.

To read or post commentaries in response to this article, see it online at http://www.AnnFamMed.org/content/15/3/204.
Key words: patient care outcomes; health care quality assessment; assessment, outcomes (health care)

Submitted March 20, 2017; accepted March 21, 2017.

\section{References}

1. Frankel BA, Bishop TF. A cross-sectional assessment of the quality of physician quality reporting system measures. J Gen Intern Med. 2016;31(8):840-845.

2. Mendelson A, Kondo K, Damberg C, et al. The effects of pay-forperformance programs on health, health care use, and processes of care: a systematic review. Ann Intern Med. 2017;166(5):341-353.

3. Caveney BJ. Pay-for-performance incentives: holy grail or sippy cup? N C Med J. 2016;77(4):265-268.

\title{
POINTICOUNTERPOINT
}

\section{Counterpoint: How Quality Reporting Made Me a Worse Doctor}

\author{
David L. Habn, MD, MS $S^{1,2}$ \\ ${ }^{1}$ Wisconsin Research and Education Network (WREN), Madison, Wisconsin \\ ${ }^{2}$ Department of Family Medicine and Community Health, University of Wisconsin School of Medicine and Public Health, Madison, Wisconsin
}

Ann Fam Med 2017;15:206-208. https://doi.org/10.1370/afm.2077.

$\mathrm{T}$

The current approach to accountability of medical care is to blend reporting of "quality measures" with "pay-for-performance" (P4P).

Benefits of this approach include use of medical evidence and population-based thinking. Limitations include use of disease-oriented instead of patientoriented measures, and arbitrary benchmarks lacking actionable information. Evidence that physician P4P strategies have improved patient care and outcomes is limited. ${ }^{1}$ Pay-for-performance incentives to maximize performance instead of incentivizing informed patient preferences can put clinicians in the position of having to choose between providing excellent individualized patient care, or being paid equitably. Linking compen-

Conflicts of interest: author reports none.

\section{CORRESPONDING AUTHOR}

David L. Hahn, MD, MS

Department of Family Medicine and Community Health

University of Wisconsin School of Medicine and Public Health 1100 Delaplaine Court

Madison, WI 53715

dlhahn@wisc.edu sation with achieving arbitrary benchmarks conflicts with practicing shared decision making wherein the quality measure is the adequacy of the shared-decision-making encounter, not the prevalence of the eventual outcome chosen by the patient. ${ }^{2}$ These perverse incentives made me a worse doctor as indicated by failing to meet the benchmarks.

\section{PATIENT SATISFACTION}

My partners complained about the conflict between good medical practice versus giving patients what they demanded (such as unneeded antibiotics and/or opioids) to increase patient satisfaction scores. System factors beyond the direct control of the clinician may also demoralize clinicians who feel they are being unfairly judged. ${ }^{3}$ In one study, whether patients chose (higher satisfaction) or were assigned (lower satisfaction) their doctor was 10 times more influential than clinician behavior. ${ }^{3}$ Might one also expect an inverse association between patient satisfaction scores and open access scheduling? I asked myself that question as I continued to keep my practice open to "work-ins," "walk-ins," and new patients. 